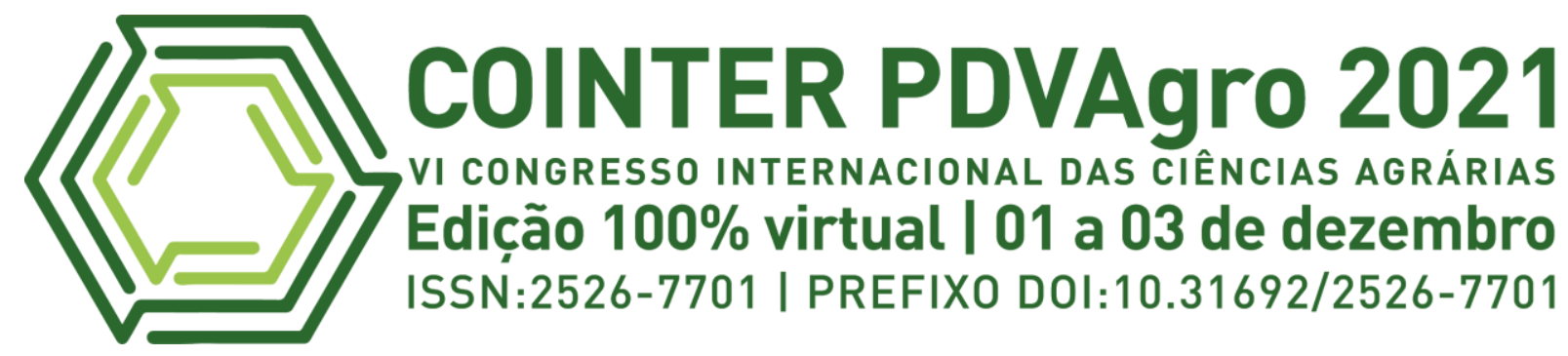

\title{
DISPERSÃO DE Nicotiana glauca GRAHAM EM ÁREAS DEGRADADAS DE CAATINGA HIPERXERÓFILA AO LONGO DO PISF
}

\author{
DISPERSIÓN DE Nicotiana glauca GRAHAM EN ÁREAS DEGRADADAS DE \\ HIPERXERÓFIL CAATINGA A LO LARGO DEL EJE NORTE DEL PISF \\ DISPERSION OF Nicotiana glauca GRAHAM IN DEGRADED AREAS OF \\ HYPERXEROPHIL CAATINGA ALONG THE NORTH AXIS OF THE PISF
}

\author{
Apresentação: Comunicação Oral \\ Eugenio Muniz Agra ${ }^{1}$; Dan Vitor Vieira Braga ${ }^{2}$ \\ DOI:https://doi.org/10.31692/2526-7701.VICOINTERPDVAgro.0280
}

\begin{abstract}
RESUMO
A Nicotiana Glauca Graham é uma espécie que tem como local de origem a Bolívia e a Argentina. Atualmente, tem se tornado uma ameaça a biodiversidade, pois pode alterar o ciclo dos nutrientes encontrados no solo. A mesma propaga-se rapidamente em locais de áreas degradadas, e secos. Devido ao tamanho da sua semente e as condições climáticas favoráveis a espécie, a Caatinga tem se tornado palco para a dispersão, principalmente no entorno do Projeto de integração do rio São Francisco com Bacias Hidrográficas do Nordeste Setentrional. Esta pesquisa tem como objetivo analisar a dispersão da Nicotiana Glauca Graham e determinar a sua ocorrência e estabelecimento em área degradadas de Caatinga externas ao PISF, visando o controle subsidiar programas de controle e erradicação. Essa pesquisa tem como base teórica Ziller (2001), Fabricante (2013), Andrade Lima (1981), Garda (1996), Shueller (2004), Carvalho (2000), Siqueira filho (2012), Zhang (1978), entre outros autores. Para a obtenção dos dados dessa pesquisa, foram realizados inventários de campo nos locais, usando parcelas onde haviam a população desta espécie. Entre os resultados obtidos, destaca-se a rápida disseminação da espécie nas áreas degradadas externas ao PISF e sua preferência para a colonização de áreas desmatadas de Caatinga, impactando a regeneração natural destas áreas. Conclui-se que há necessidade do controle imediato da espécie nas áreas do PISF, principalmente nas intermediações do PISF no município de Salgueiro-PE e Terra Nova-PE, de forma a minimizar ou erradicar os indivíduos desta espécie exótica das localidades e, com isso, evitar o surgimento de novos casos de invasão biológica por Nicotiana glauca Graham em outras partes do PISF na região.
\end{abstract}

Palavras-Chave: Fumo-Bravo, Bioinvasão, Caatinga

\footnotetext{
${ }^{1}$ Licenciatura em Ciências Biológicas, Faculdade de Ciências Humanas do Sertão Central-(FACHUSC), eugenioagra123@gmail.com.br

${ }^{2}$ Mestre em Gestão e Políticas Públicas Ambientais, Faculdade de Ciências Humanas do Sertão Central(FACHUSC), dan.braga@ fachusc.com
} 


\title{
RESUMEN
}

Nicotiana Glauca Graham es una especie que tiene como origen a Bolivia y Argentina. Actualmente, se ha convertido en una amenaza para la biodiversidad, ya que puede alterar el ciclo de nutrientes que se encuentran en el suelo. Se propaga rápidamente en áreas degradadas y secas. Por el tamaño de su semilla y las condiciones climáticas favorables para la especie, la Caatinga se ha convertido en un escenario de dispersión, principalmente en los alrededores del Proyecto de Integración del Río São Francisco con las Cuencas Hidrográficas Norte-Nordeste. Esta investigación tiene como objetivo analizar la dispersión de Nicotiana Glauca Graham y determinar su ocurrencia y establecimiento en áreas degradadas de Caatinga fuera del PISF, con miras a subsidiar programas de control y erradicación. Esta investigación se basa teóricamente en Ziller (2001), Manufacturer (2013), Andrade Lima (1981), Garda (1996), Shueller (2004), Carvalho (2000), Siqueira Filho (2012), Zhang (1978), entre otros. autores. Para obtener los datos de esta investigación, se realizaron inventarios de campo en los lugares, utilizando parcelas donde había una población de esta especie. Entre los resultados obtenidos se destaca la rápida propagación de la especie en áreas degradadas fuera del PISF y su preferencia por la colonización de áreas deforestadas de Caatinga, impactando la regeneración natural de estas áreas. Se concluye que existe la necesidad de un control inmediato de la especie en las áreas del PISF, especialmente en los intermediarios del PISF en los municipios de Salgueiro-PE y Terra Nova-PE, con el fin de minimizar o erradicar individuos de esta especie exótica del localidades y, con ello, evitar la aparición de nuevos casos de invasión biológica por Nicotiana glauca Graham en otras partes del PISF de la región.

Palabras Clave: Humo salvaje, Bioinvasión, Caatinga.

\begin{abstract}
Nicotiana Glauca Graham is a species that has Bolivia and Argentina as its place of origin. Currently, it has become a threat to biodiversity, as it can alter the cycle of nutrients found in the soil. It spreads quickly in degraded and dry areas. Due to the size of its seed and the favorable climatic conditions for the species, the Caatinga has become a stage for dispersal, mainly in the surroundings of the São Francisco River Integration Project with the NorthNortheast Hydrographic Basins. This research aims to analyze the dispersion of Nicotiana Glauca Graham and determine its occurrence and establishment in degraded areas of Caatinga outside the PISF, with a view to subsidizing control and eradication programs. This research is theoretically based on Ziller (2001), Manufacturer (2013), Andrade Lima (1981), Garda (1996), Shueller (2004), Carvalho (2000), Siqueira Filho (2012), Zhang (1978), among others authors. In order to obtain data from this research, field inventories were carried out at the sites, using plots where there was a population of this species. Among the results obtained, the rapid spread of the species in degraded areas outside the PISF and its preference for colonization of deforested areas of Caatinga stands out, impacting the natural regeneration of these areas. It is concluded that there is a need for immediate control of the species in the PISF areas, especially in the PISF intermediaries in the municipalities of Salgueiro-PE and Terra Nova-PE, in order to minimize or eradicate individuals of this exotic species from the localities and, with that, , prevent the emergence of new cases of biological invasion by Nicotiana glauca Graham in other parts of the PISF in the region.
\end{abstract}

Keywords: Wild Smoke, Bioinvasion, Caatinga.

\section{INTRODUÇÃO}

O processo de invasão de um ecossistema por uma planta exótica, se da quando uma 
espécie de um determinado local é introduzida e se naturaliza, dispensando-se e alterando as características biológicas de um ecossistema. As propagações dessas plantas afetam primeiramente o funcionamento natural e desenvolvimento das espécies locais, podendo inclusive comprometer a produtividade dos sistemas agrícolas locais (PROFIRO; BRAGA, 2020).

As espécies bioinvasoras, são consideradas desde o início da década passada a segunda maior ameaça a biodiversidade, estando logo atrás da destruição de habitats pela exploração humana. (ZILLER, 2001).

A invasão de plantas exóticas no Brasil é um problema que afeta nossa biodiversidade há muito tempo. Porém, foi um problema deixado de lado por anos, principalmente pelas instituições de pesquisa, quanto por aquelas que trabalham com a conservação do meio ambiente. Apenas na década de 1980, pesquisadores e conservacionistas começaram a dar mais atenção aos problemas provocados pelas espécies invasoras. (PARRELLA,2021).

Segundo Fabricante e Siqueira filho (2003), o processo de invasão se dá através da semelhança entre o local de origem e o local de introdução da espécie. No Brasil, muitas das exóticas invasoras estão situadas na Caatinga, região que vem sofrendo pressões antrópicas e degradação no seu meio físico. Isso faz com que a localidade seja o cenário ideal para a dispersão de sementes de determinadas espécies. (SILVA; RAMOS, 2019).

De acordo com a Lista de Espécies da Flora do Brasil (2014), existem mais de 130 espécies naturalizadas registradas na Caatinga. Somente nas áreas de influência das obras do Projeto de Integração do Rio São Francisco com Bacias Hidrográficas do Nordeste Setentrional (PISF), já foram identificadas mais 60 espécies exóticas, sendo 10\% destas consideradas exóticas invasoras. (FABRICANTE; SIQUEIRA FILHO, 2012).

Dentre essas espécies está a Nicotiana glauca Graham pertencente à família Solanaceae. Popularmente, esta planta é conhecida na área de abrangência do PISF como conhecida como “Fumo-Bravo”, “Tabaco-Arbóreo”' e “Charuto do rei” (SCHUELLER, 2004; ZHANG, 1978).

Devido ao tamanho reduzido dos propágulos, a espécie tem sido dispersada rapidamente e a longas distâncias por automóveis e máquinas, afetando a vegetação local. (FABRICANTE; 2013) e inclusive, tendo relatos recentes de sua disseminação em áreas agrícolas limítrofes à Área Diretamente Afetada (ADA) pelas obras dos canais e barragens do PISF (PROFIRO; BRAGA, 2020).

Essa pesquisa tem como objetivo analisar a dispersão da Nicotiana glauca apartir das áreas degradadas de Caatinga Hiperxerófita, localizadas próximas ao canal do eixo norte do Projeto 
de Integração do Rio São Francisco com Bacias Hidrográficas do Nordeste Setentrional em Umãs, terceiro distrito da cidade de Salgueiro, Pernambuco.

\section{FUNDAMENTAÇÃO TEÓRICA}

A Caatinga é o único bioma exclusivamente brasileiro e ocupa uma área equivalente a $11 \%$ do território nacional, estando à maior parte na região Nordeste (OLIVEIRA JUNIOR; BRAGA, 2019). Rico em diversidade de fauna e flora, apesar da sua importância, é um ecossistema cujo desmatamento vem se agravando de forma acelerada. Nos últimos anos, pesquisas apontam que em torno de $46 \%$ da área desse bioma está desmatada ou passando por este processo (MINISTÉRIO DO MEIO AMBIENTE, 2014).

Ressalta-se que, as alterações impostas nos ecossistemas por ações antrópicas são profundas e geram grandes impactos, muitos considerados irreversíveis, destacam-se entre elas a invasão biológica, que é apontada como a segunda causa de extinção das espécies no planeta (PIMM, et al 1995).

Segundo GARDA (1996), os solos nordestinos estão sofrendo um processo intenso de desertificação, devido à substituição da vegetação natural por culturas, principalmente através de queimadas. Esse processo já é considerado irreversível. Devido à falta de água, práticas comuns no Nordeste, como a irrigação, estão levando à salinização dos solos, aumentando ainda mais a evaporação da água contida neles e acelerando, desta maneira, o processo de desertificação. De acordo com o autor, a presença da vegetação adaptada na Caatinga tem transformado o Nordeste brasileiro num imenso deserto.

Muitas das espécies introduzidas ocorrem acidentalmente ou intencionalmente, quase sempre com finalidades econômicas, onde passam a adaptar-se ao clima local e começam a competir com as espécies nativas, desencadeando problemas gravíssimos, tais como: alteração das características naturais, o funcionamento de processos ecológicos, afetando diretamente a resiliência dos ecossistemas, a redução de populações autóctones e perda da biodiversidade (ZILLER, 2001).

De acordo com as definições adotadas pela Convenção Internacional sobre Diversidade Biológica (CDB, 1992), uma espécie é considerada exótica (ou introduzida) quando situada em um local diferente do de sua distribuição natural por causa de introdução mediada por ações humanas, de forma voluntária ou involuntária. Se a espécie introduzida consegue se reproduzir e gerar descendentes férteis, com alta probabilidade de sobreviver no novo hábitat, ela é considerada estabelecida. Caso a espécie estabelecida expanda sua distribuição no novo hábitat, ameaçando a biodiversidade nativa, ela passa a ser considerada uma espécie exótica invasora. 
Esse processo de bioinvasão se estabelece de forma rápida por meio da dispersão de sementes, aos quais se atribui essa capacidade de distribuir a germinação no tempo e espaço, pois o papel biológico da semente é conservar e propagar a espécie, podendo germinar quando as condições são adequadas para a manutenção do crescimento da plântula e subsequente o desenvolvimento da planta (CARVALHO; NAKAGAWA, 2000).

Segundo Fabricante e Siqueira Filho (2012), existem mais de 130 espécies naturalizadas registradas na Caatinga. Somente nas áreas de influência das obras do Projeto de Integração do Rio São Francisco com Bacias Hidrográficas do Nordeste Setentrional (PISF), já foram identificadas mais 60 espécies exóticas, sendo 10\% destas consideradas exóticas invasoras.

Entre algumas dessas invasoras está a Nicotiana glauca Graham.

A espécie possui compostos tóxicos para a maioria dos herbívoros, incluindo moléculas com efeito inseticida, o que as tornam resistente à herbívora. Essas características, associadas ao seu rápido crescimento, faz com que seja considerada uma invasora com risco ecológico ainda pouco conhecido. A espécie é rica em Nornicotina, que possui diversos usos em ervanária, sendo usada nas misturas de tabaco tradicionalmente fumadas pelos povos Ameríndios (SCHUELLER, 2004).

Arbustiva e de rápido crescimento, possui caules lenhosos que chegam a atingir de 3 a 6 metros de altura, com tendência ruderal. A espécie aparece com frequência em terrenos incultos ou abandonados, zonas de remoção de terras, entulheiras e à beira de caminhos. (SCHUELLER, 2004, ZHANG,1978)

Devido ao trânsito intenso de pessoas, animais e automóveis, suas sementes ultrapassam as barreiras geográficas, chegando a tomar uma grande proporção no território, o que resulta na competição direta entre as espécies nativas, e alterações físicas no solo (BIOMONTE, 2020).

O que dificulta o controle dessa espécie é a falta de conhecimento sobre a biologia da mesma. Isso significa, que para obter um controle efetivo é necessário conhece-la. Os usos de práticas inadequadas em momentos impróprios podem ocasionar resultados reversos (IFOPE,2019).

\section{METODOLOGIA}

\section{Área de estudo}

A pesquisa foi realizada no eixo Norte do Projeto de Integração do Rio São Francisco com bacias hidrográficas do Nordeste setentrional (PISF), em Umãs terceiro distrito da cidade de Salgueiro em Pernambuco (Figura 1).

O local tem cerca de 2.100 habitantes contendo áreas de produções agrícolas em seu redor 
e parte da caatinga em diferentes condições de conservação. O clima da região é semiáridoquente, com solos rasos e pedregosos (IBGE, 2020).

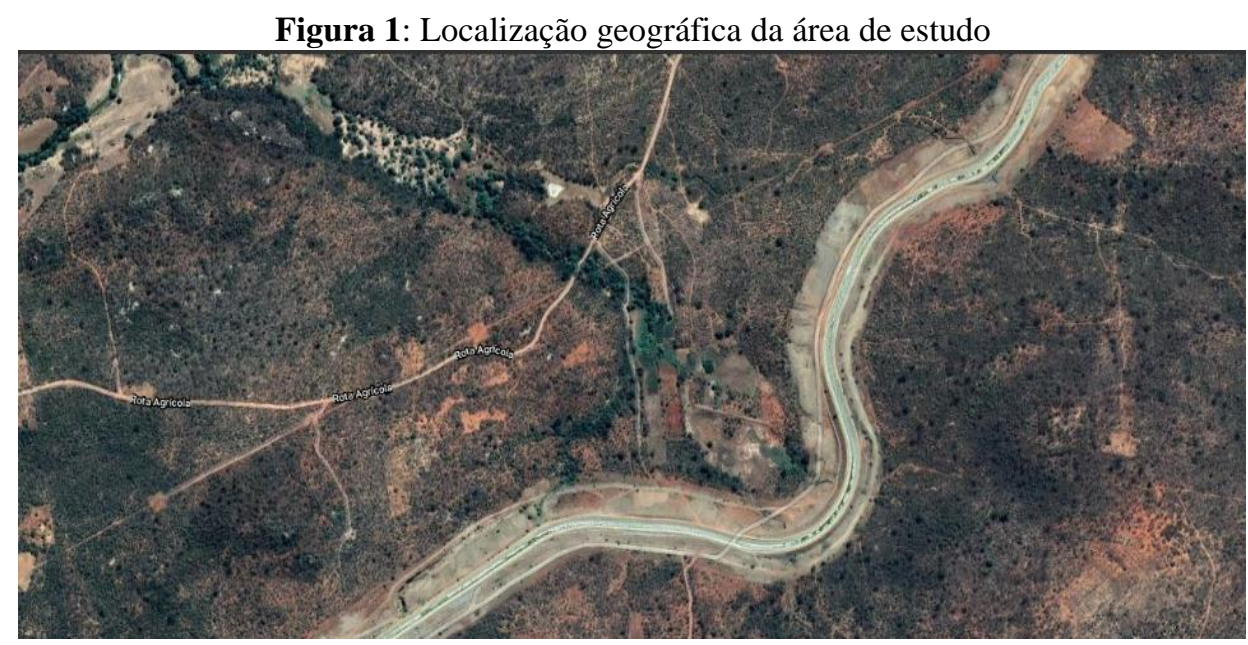

Fonte: Modificado de Google Maps, 2020.

A comunidade do distrito de Umãs tem cerca de 2.100 habitantes (IBGE, 2020), contendo áreas de produções agrícolas em seu redor e parte da Caatinga Hiperxerófita em diferentes condições de conservação. O clima da região é semiárido-quente, com solos rasos e pedregosos (IBGE, 2020).

A coleta de dados em campo ocorreu de Julho a Setembro de 2021, onde foram implantadas 12 parcelas temporárias de $100 \mathrm{~m}^{2}(10 \mathrm{x} 10 \mathrm{~m})$, sendo grupos de três parcelas em cada condição analisada (Condição 1 - Margem do canal de adução na Área Diretamente Afetada do PISF; Condição 2 - Margem da Barragem Serra do Livramento na Área Diretamente Afetada do PISF; Condição 3 - Áreas cultivada limítrofe à ADA do PISF; Condição 4 - Áreas Caatinga degradada limítrofe à ADA do PISF ).

Cada grupo de parcelas localizado nas áreas degradadas, ou cultivadas, externas à ADA do PISF foi implantado a partir do limite da área com vegetação suprimida e de forma pependicular à poligonal do empreendimento. Assim, a parcela 1 de cada grupo iniciava no limite da supressão, a parcela 2 iniciava à $20 \mathrm{~m}$ da área suprimida pelo PISF e a parcela 3 iniciava à 40m do PISF (Figura 2). 
Figura 02: Desenho amostral da distribuição dos grupos de parcelas implantadas interna e externamente à Área Diretamente Afetada (ADA) do PISF.

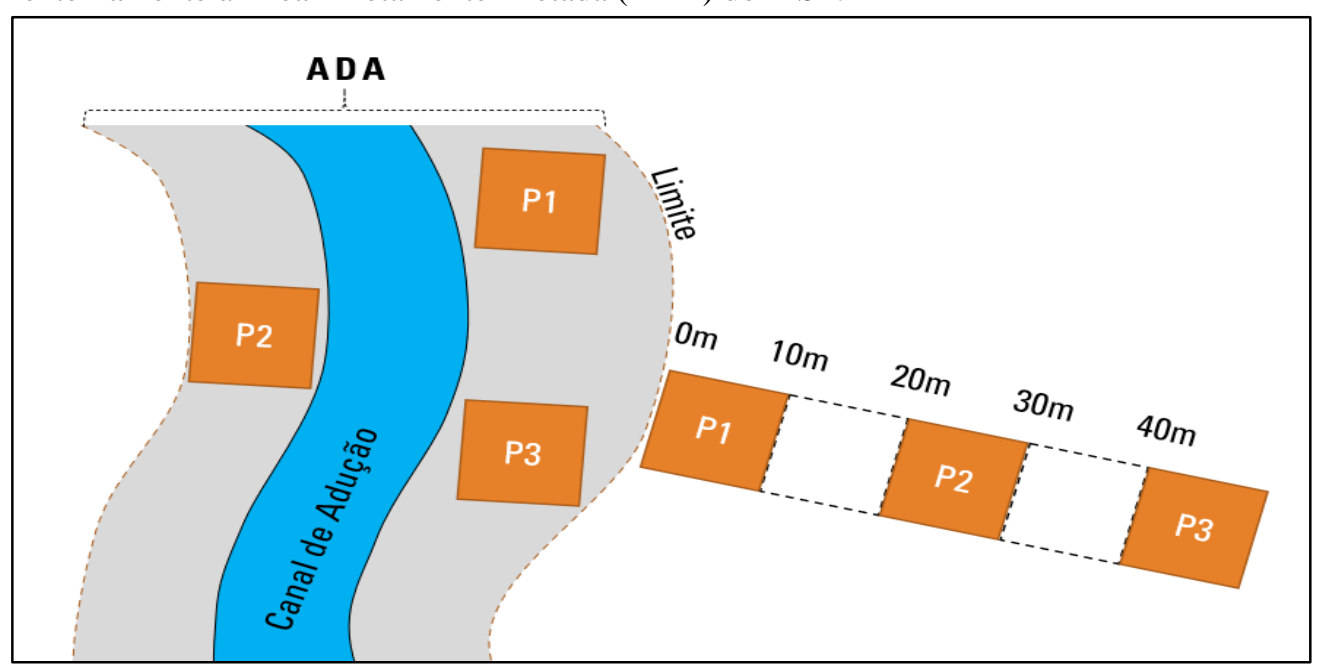

Fonte: Própria, 2021.

Essa disposição de cada grupo de parcelas em campo permitiu avaliar se existia um gradiente de dispersão de $N$ glauga a parti do PISF, determinando se essa espécie invasora havia extrapolado os limistes do empreemdiemto e se estabelecendo com sucesso nas áreas degradadas de Caatinga do seu entorno. Em cada parcela, foram inventariados todos os idivíduos vivos de $N$ glauga para a determinação da abundância total desta espécie na área estudada. A variação da Abundância Total de cada condição foi avaliada através do teste ANOVA e as médias foram comparadas utilizando o Teste T. As ánelises estatisticas e os respectivos gráficos foram eleaborados utilizando o programa Statistica, versão 7.0.

\section{RESULTADOS E DISCUSSÃO}

De acordo com os dados obtidos, observou-se que houve uma variação significativa $(\mathrm{F}=25,662 ; \mathrm{p}=0,00)$ da Abundância Total de $N$ glauca nas áreas degradadas na ADA do PISF e no seu entorno imedito, indicando que a quantidade de indivíduos desta espécie invasora apresentou uma grande variação em campo (Gráfico2). 
Gráfico 01: Análise da variação da Abundância Total de N. glauca em degradadas de Caatinga localizadas na ADA e entorno imediato do PISF.

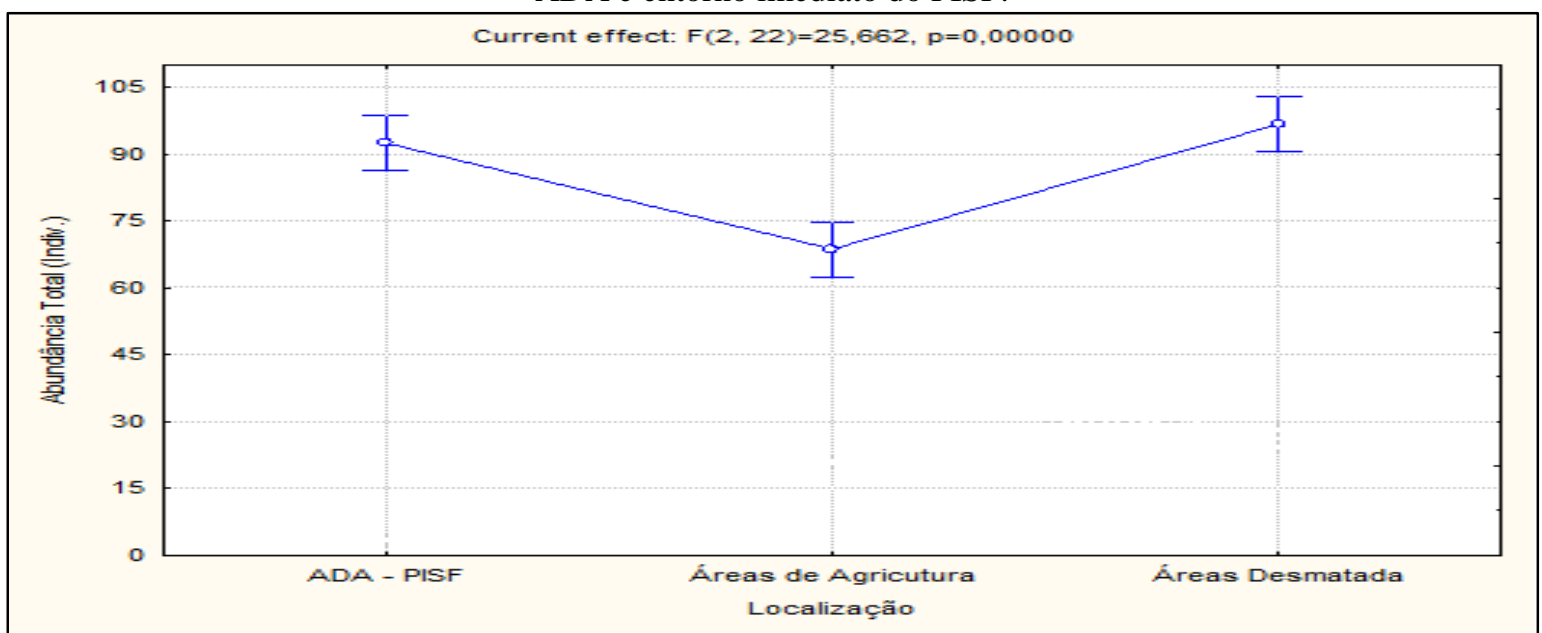

Fonte: Própria (2021)

O resultado acima descrito, pode estar associado ao tipo de distribuição espacial agrupada das populações desta espécie na área de estudo, o que faz com que a espécie obtenha uma predisposição natural em formar adensamentos (Figura 3). com quantidades variáveis de indivíduos a depender do tempo em que a população local em questão se estabeleceu (PROFIRO; BRAGA, 2020).

Figura 03: Populações locais de N. glauca observados na área de estudo. A. Margem esquerda do canal de adução no Eixo Norte; B. Margem direita do canal; C. Proximidades da Estação de Bombeamento; D. Área de produção agrícola limítrofe ao PISF.

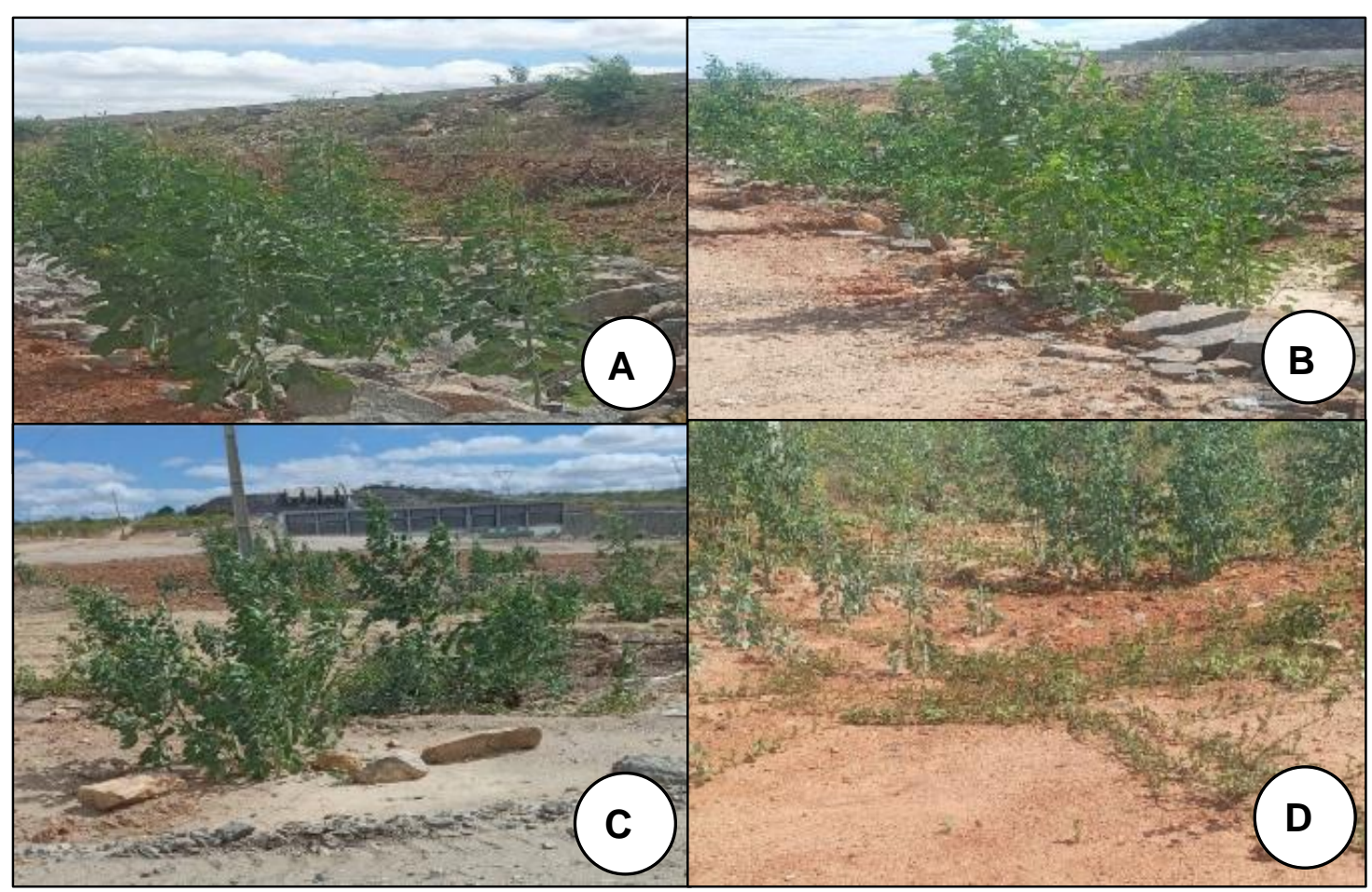

Fonte: Própria (2021)

Quando se analisa apenas as duas condições de áreas degradadas externas ao PISF (Áreas 
desmatada x Áreas de cultivo), observaou-se que a Abundância Total de N. glauca variou de forma significativa $(\mathrm{F}=111,33, \mathrm{p}=0,00)($ Gráfico 2$)$.

Gráfico 02: Análise da variação da Abundância Total de $N$. glauca em áreas desmatadas e áreas de cultivo localizadas próximas ao PISF.

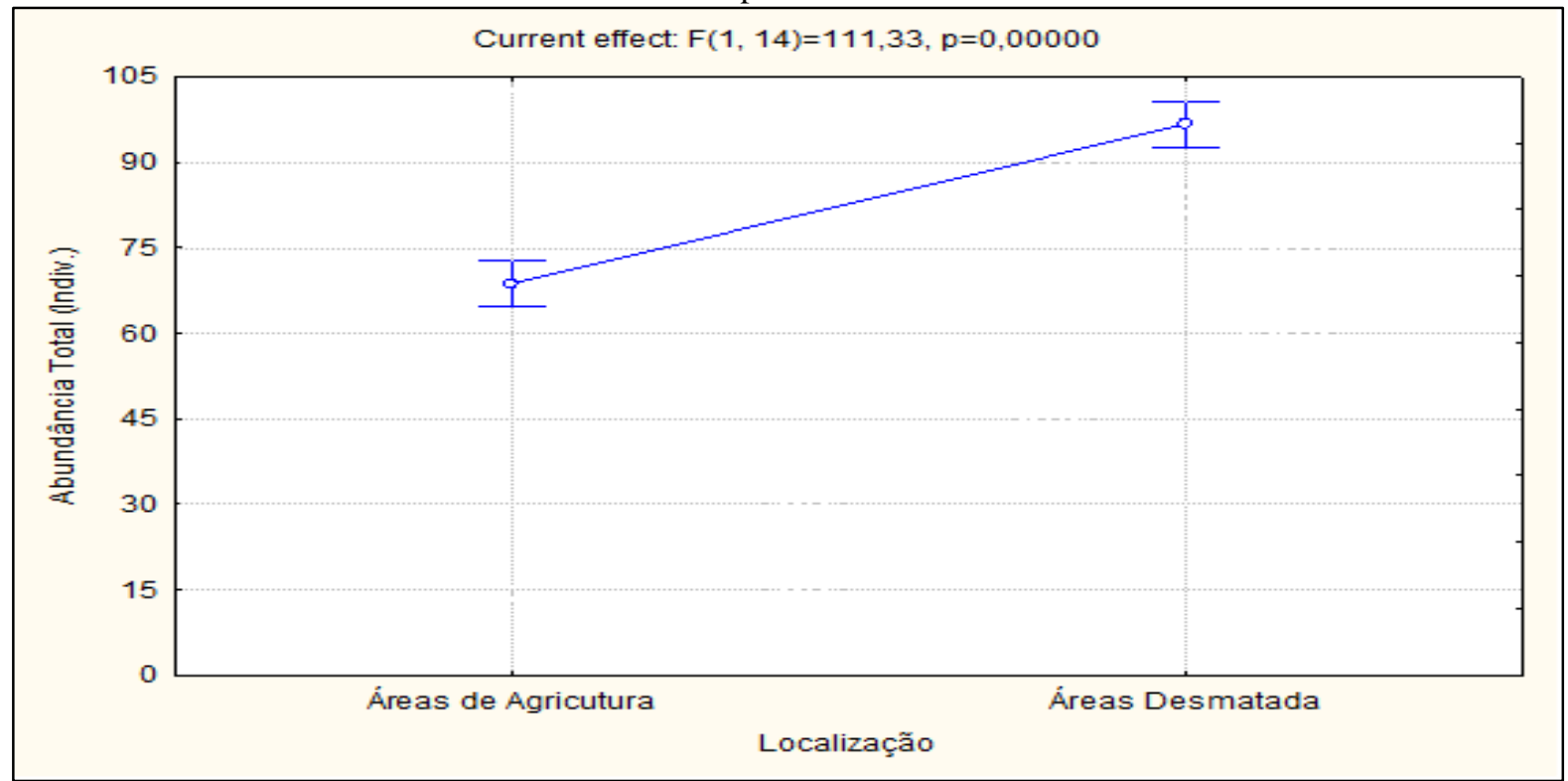

Fonte: Própria (2021)

Ao se avaliar a ocorrência de um gradiente de dispersão de $N$ glauga a parti do PISF a partir das parcelas implantadas nas margens da ADA, observou-se que não huve diferença significativa $(\mathrm{F}=2,0526, \mathrm{p}=0,1523)$ (Gráfico 3). Este resultado demosntrou que $N$. Glauca já extrapolaou os limistes do empreemdiemto e se estabeleceu com sucesso nas áreas degradadas de Caatinga do seu entorno.

Gráfico 03 - Análise da variação da Abundância Total de $N$. glauca em diferentes distâncias a partir da margem da ADA do PISF.

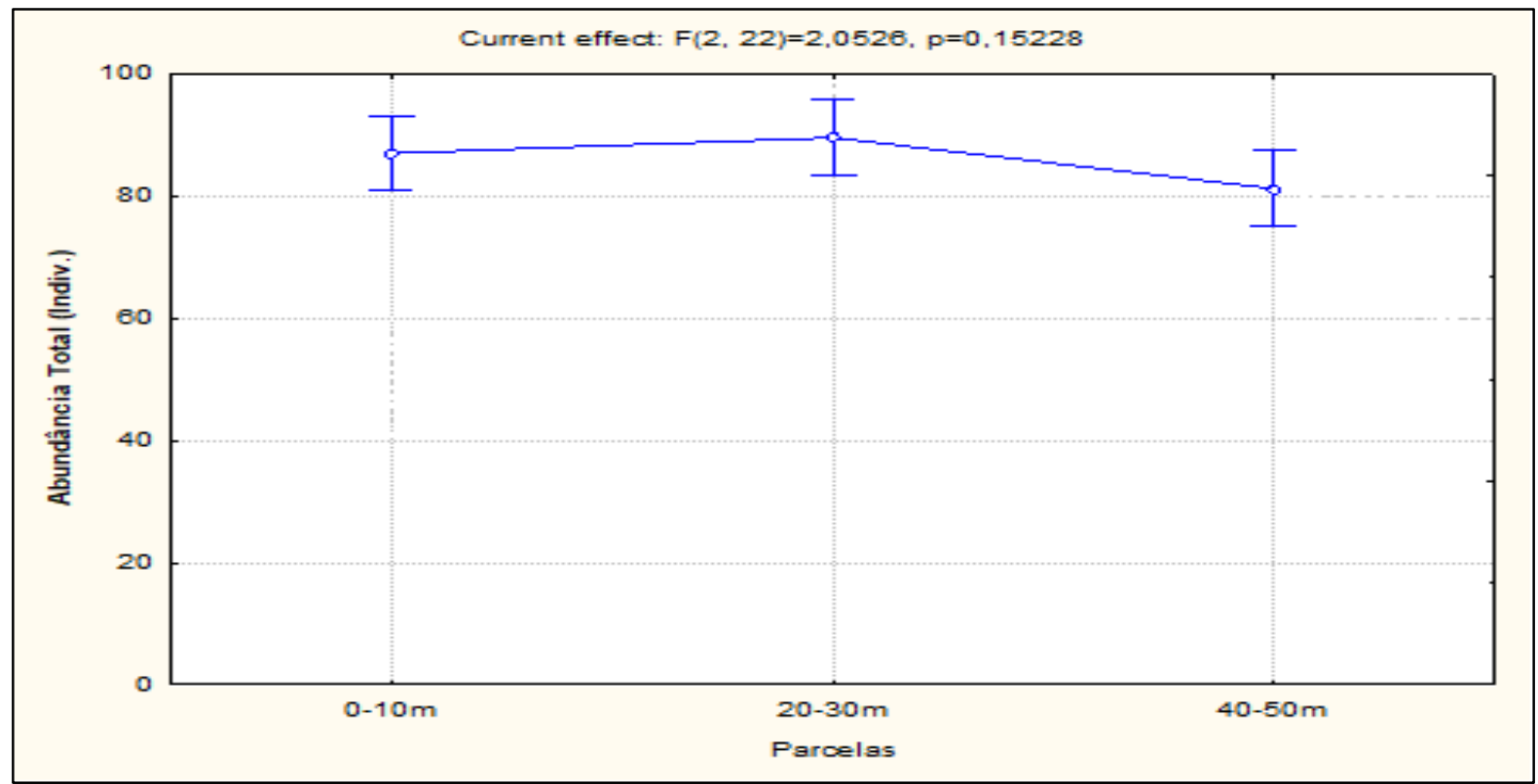

Fonte: Própria (2021) 
Ao se comparar as médias observadas para a Abundância Total de N. glauca nas áreas degradadas na ADA do PISF e nas duas condições de areas degradadas externas ao empreemdimento (Áreas de Agricultura e Áreas de vegetção desmatada), observou-se que houve diferenças significativas apenas entre a quantidade de indviduos observados na ADA e nas áreas de cultivo (Teste $\mathrm{t}=4,5371 ; \mathrm{p}=0,002$ ), havendo maior quantidade de indivíduos de N. glauca presentes na ADA do PISF (Média=92,44+12Indivíduos/parcela) (Gráfico 4A).

Os resultados demonstram que a quantidade de indivíduos observados de $N$. glauca nas áreas de Caatinga desmatadas foram estatisticamente semelhantes (Teste $\mathrm{t}=0,8958$ - $\mathrm{p}=0,3965$ ), ao observado na ADA do PISF (Grafico 4B), marco zero da invação biológica desta espécie exótica na área de estudo.

Gráfico 04: Comparação das médias da Abundância Total de N. glauca em diferentes condições de áreas degradadas. A. Comparação entre a ADA e as áreas de Agricultura; B. Comparação entre a ADA e as áreas desmatadas.

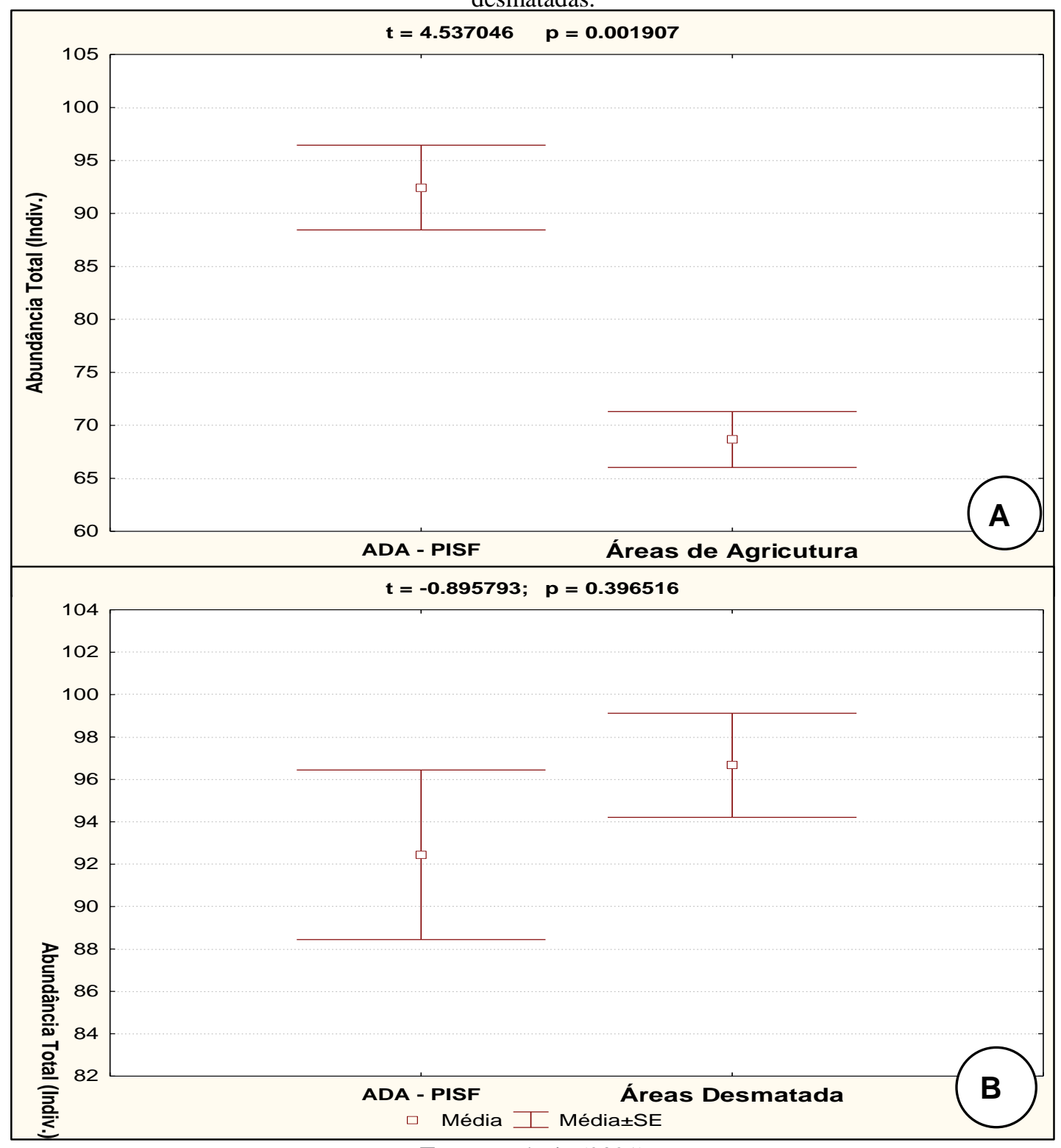

Fonte: Própria (2021) 
Ao se comparar as médias observadas para a Abundância Total de $N$. glauca nas duas ondições de áreas degradadas externas à ADA do PISF (Áreas de Agricultura e Áreas de vegetção desmatada), observou-se que houve diferença altamente significativa (Teste $t=-$ 10,583; $\mathrm{p}=0,00$ ), havendo maior quantidade de indivíduos de $N$. glauca presentes na ADA do

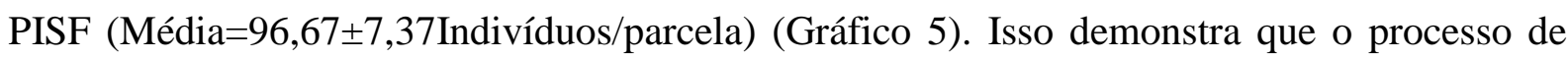
invasão biológica de $N$. glauca está mais acentuado nas áreas de Caatinga desmatadas do que nas áreas de agricultura no entorno da obra, havendo uma preferência desta espécie por este tipo de condição. Isso ameaça os processos de regeneração natural destas áres de Caatinga desmatadas e amplia o potencial invasor de $N$. glauca na área de estudo.

Gráfico 05 - Comparação das médias da Abundância Total de N. glauca entre as áreas de Agricultura e as áreas de Caatinga desmatadas localizadas no entorno imediato do PISF.

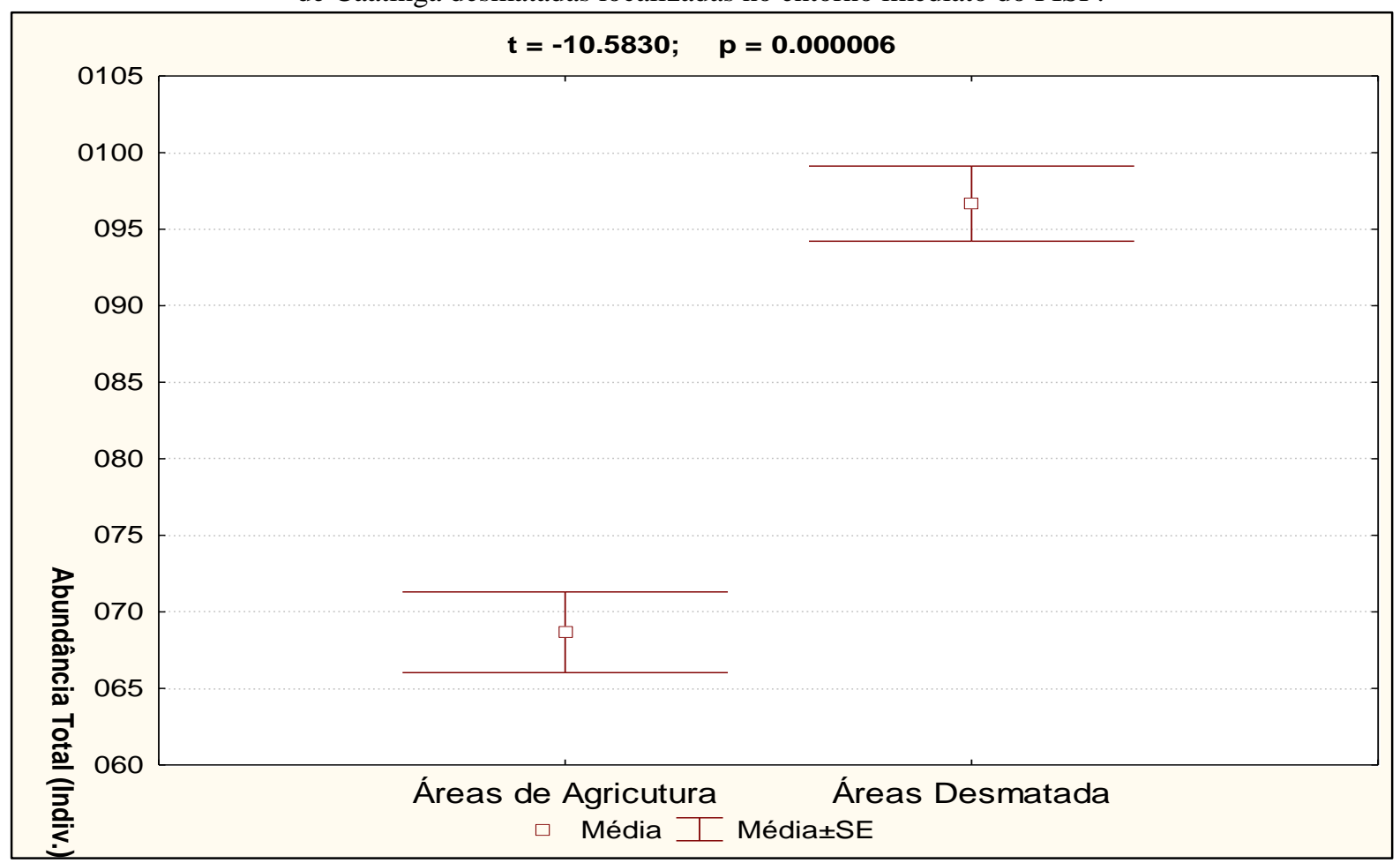

Fonte: Própria (2021)

Os dados aqui apresentados demonstram que $N$. glauca está se estabelecendo com sucesso nas áreas degradadas de Caatinga e nas áreas de cultivo no entorno do PISF. A rápida propagação da espécie torna urgente a necessidade de programas de monitoramento em áreas naturais, dentre outras iniciativas, ratificando a proposta de Matos e Pivello (2009). Segundo estes autores, no cenário apresentado na área de estudo é preciso que seja implementada técnicas de controle e erradicação de espécies exóticas invasoras, como N. glauca.

Conforme Karam (2008, p151), as espécies invasoras "obtêm mais facilmente os recursos naturais necessários (água, luz e nutrientes), tornando-as grandes competidoras em meio às 
culturas". Isso aumenta o seu potencial competidor e, consequentemente, dependendo dos hábitos e da densidade das exóticas invasoras no Campo, podem interferir negativamente na produtividade das áreas cultivadas e na capacidade de regeneração de áreas naturais.

Essa situação é agravada em espécies invasoras com características alelopáticas, onde, através da produção e liberação de toxinas que penetram no solo, impedem a germinação, crescimento, ou reprodução normal de outras espécies (PROFIRO; BRAGA, 2020).

O desenvolvimento de $N$. glauca é rápido, sendo capaz de atingir sua maturidade em pouco tempo. A produção de sementes é elevada (produzem em grandes quantidades) e de tamanho muito pequeno. Tornando-as facilmente dispersas pelo vento, água e animais, acelerando o processo de colonização de novas áreas (AGRA, 2012).

Apesar da grande ameaça oferecida pelas espécies exóticas invasoras à biodiversidade nativa e aos processos econômicos, muito poucas ações concretas existem atualmente no Brasil para combatê-las (MATOS; PIVELLO, 2009). Embora o PISF possua um Plano Básico Ambiental que preveja o monitoramento desta espécies, observa-se que na área de estudo não foi executada nenhuma ação eficaz para a erradicação desta de $N$. glauca e, com isso, atualmente ela esta amenando sua área de colonização, dispersando-se para cada vez mais longe do empreendimento.

Além disso, tendências que predominam na sociedade atual, como a crescente fragmentação dos habitats nativos remanescentes para uso econômico, ou o intenso trânsito de pessoas, equipamentos de construção civil e maquinários favorecem fortemente a dispersão desta espécies para outras áreas do Bioma Caatinga (AGRA, 2012). Medidas preventivas, como programas de informação à população e programas de monitoramento em áreas naturais, dentre outras iniciativas, devem ser implementadas juntamente com estudos para o desenvolvimento de técnicas de controle e erradicação desta espécies exóticas invasoras oriunda das obras de iplementação do PISF (PROFIRO; BRAGA, 2020).

\section{CONCLUSÕES}

De acordo com os fatos citados, as características do local favorecem a dispersão de N glauca para áreas externas ao PISF, principalmente áreas de Caatinga onde houve supressão vegetal. A degradação da paisagem baixa e o seu impacto na diversidade biológica local tornam estes locais suscetíveis ao estabelecimento e colonização por $N$. glauca e, com isso, os processos naturais de regeneração são impactados.

Desta forma, a N. glauca nas áreas degradadas do PISF e em seu entorno imediato, ocasionando uma competição direta com demais espécies locais e até mesmo com as cultivares 
implantadas nas áreas agrícolas. Faz-se necessário o manejo integrado desta espécie exótica e invasora, minimizando os prejuízos causados na economia e no ecossistema local.

Os resultados desta pesquisa demonstram a necessidade do controle imediato da invasão biológica por Nicotiana glauca Graham (Solanaceae) nas áreas do PISF, uma vez que no período de 10 anos, a espécie já se estabeleceu com sucesso fora das área do empreendimento.

\section{REFERÊNCIAS}

AGRA, C. Biologia floral de Nicotiana glauca Graham (Solanaceae) como determinante do seu potencial invasor em área degradadas pelo Projeto de Integração do São Francisco - PISF. Monografia (Licenciatura em Ciências Biologicas). Salgueio: FACHUSC. 2012. 40p.

BIOMONTE, Plantas invasoras exóticas: Riscos á Biodiversidade de Áreas Agrícolas. Disponível em: http://biomonte.com.br/artigos/plantas-invasoras-exoticas-riscosabiodiversidade-de-areas-agricolas/. Acesso em: 30 Set. 2020

CDB. Panorama da Biodiversidade Global 3. Brasília: Ministério do Meio Ambiente, Secretaria de Biodiversidade e Florestas (MMA), 1992

CARVAlHO, N. M.; NAKAGAWA, J. Sementes: ciência, tecnologia e produção. 4.ed. Jaboticabal: FUNEP. 2000. 588 p.

EMPRESA BRASILEIRA DE AGROPECUÁRIA (EMBRAPA). Plantas daninhas. Disponivel em: https://www.embrapa.br/tema-plantas-daninhas/sobre-o-tema Acesso em: 29/ Jul.2020.

FABRICANTE, et al. ATRIBUTOS ECOLÓGICOS DA BIOINVASORA Nicotiana Glauca GRAHAM (SOLANACEAE) E AVALIAÇÃO DA SUSCEPTIBILIDADE DE SUA OCORRÊNCIA NO BRASIL, Santa Maria: Ciênc. Florest. vol.25 no.4, Dec. 2015.

GARDA, E. C. 1996. Atlas do meio ambiente do Brasil. Brasília, Editora Terra Viva.

INSTITUTO BRASILEIRO DE GEOGRAFIA E ESTATÍSTICA (IBGE). Cidades@. Pernambuco. Salgueiro. Panorama. 2019. Disponível em: https://cidades.ibge.gov.br/brasil/pe/salgueiro/panorama. Acesso em: 30/ Set. 2020.

MATOS; PIVELLO. O IMPACTO DAS PLANTAS INVASORAS NOS RECURSOS NATURAIS DE AMBIENTES TERRESTRES - ALGUNS CASOS BRASILEIROS, Cienc. Cult. vol.61 no.1 São Paulo 2009

MINISTÉRIO DO MEIO AMBIENTE (MMA). Disponível em: https://www.mma.gov.br/estruturas/chm/_arquivos/port_inva. Acesso em: 25 Set. 2020.

PIMM, S. I.; RUSSEL, G. J. GITTELMAN, J. L.; BROOKS, T. M. The future of biodiversity, 1995.

OLIVEIRA JÚNIOR, M. G.; BRAGA, D.V.V. 2019. Variação florística ao longo da sucessão 
ecológica em unidade de conservação de Caatinga hiperxerófita. In: ANDRADE, D. F. (Ed.). Semiárido Brasileiro. Belo Horizote: Editora Poisson. Volume 3. ISBN: 978-85-7042154-8. DOI: 10.36229/978-85-7042-154-8.CAP.02. Disponível em: https://www.poisson.com.br/livros/semiarido/volume3/. Acesso em: 20 jan. 2021.

SILVA, E. B.; RAMOS, A. B. 2019. Levantamento florístico e dispersão de sementes em uma área degradada de Caatinga hiperxerófila. In: ANDRADE, D. F. (Ed.). Semiárido Brasileiro. Belo Horizote: Editora Poisson. Volume 3. ISBN: 978-85-7042-154-8. DOI: 10.36229/978-85-7042-154-8.CAP.01.

Disponível

em:

https://www.poisson.com.br/livros/semiarido/volume3/. Acesso em: 20 jan. 2021.

PROFIRO, M. L.; BRAGA, D. V.V. Invasão Biológica de Nicotiana Glauca Graham em Áreas Produtivas as Margens do PISF. In: Anais do Congresso Internacional das Ciêcias Agrárias. 2020. Edicão Online. DOI: https://doi.org/10.31692/25267701.VCOINTERPDVAgro.0451. Acesso em: 20 jan. 2021.

IFOPE, $O$ impacto das plantas daninhas na ágricultura. Disponivel em: https://blog.ifope.com.br/o-impacto-das-plantas-daninhas-na-agricultura/. Acesso em: 30 Set 2020.

PARRELLA, D. Os problemas das plantas exóticas invasoras. Plantas exóticas invasoras. São Paulo: Genoma florestal, 2021. Disponível em: https:// https://geonomaflorestal.com.br/plantas-exoticas-invasoras/ 